\title{
How to Create an Effective Thematic Map
}

\author{
Doina VASILCA* \\ Faculty of Geodesy, Technical University of Civil Engineering Bucharest, \\ 124 Lacul Tei Boulevard, Bucharest, Romania \\ *corresponding author: doinavasilca@yahoo.com
}

BulletinUASVM Horticulture 76(2) / 2019

Print ISSN 1843-5254, Electronic ISSN 1843-5394

DOI:10.15835/buasvmcn-hort: 2019.0035

\begin{abstract}
Considering the evolution of automatic mapping programs and the huge amount of available data, the key elements that go into creating thematic maps are presented so that those less familiar with map-making might be able to craft accurate, reliable and illustrative maps.

Here, we used ArcGIS Pro in order to exemplify the process of creating thematic maps presenting correlations between the number of emergency/total 112 calls and the population of Romanian counties. These freely-available data were classified using Natural Brakes, Quantile, Equal Interval, Geometric Interval, Standard Deviation, Defined Interval and Manual Interval, so as to highlight their relevant aspects. The value of the goodness of absolute deviation fit was calculated for each method and each data set. The maps were then created using combined choropleth and proportional symbol methods. The ratio between the total number of 112 calls and the county populations, structured into five classes, has been represented using choropleth method. On the resulting map, emergency calls have been represented with proportional symbols. Furthermore, aspects related to the other map elements were presented all in one place, in order to create a thematic map that would be easy to understand and interpret.

The findings of the present paper could be used by those who want to represent their own data in a very suggestive and reliable manner, without having had any cartographic training beforehand. They could also more easily interpret their datasets and be able to take the necessary steps in their own domains of activity.
\end{abstract}

Keywords: classification, emergency calls, symbolization, thematic maps

\section{Introduction}

The population's health is one of the conditions that need to be taken into account for the sustainable development of any country. Therefore, creating effective thematic maps using modern cartographic capabilities could be very helpful in this area of activity.

Today's modern technology and numerous software suites, many of which are freely available online, allow any interested party to create their own maps in order to meet their particular needs. So as to better illustrate their presented facts, various publications aimed at the general public make frequent use of thematic maps, but which are seldom designed by cartographers. Even though these might be graphically attractive, such maps may not render the presented reality in the clearest terms for their intended audience.

Considering the above, we aimed to clarify a very important aspect involved in creating such maps, namely the classifying method for the represented data, as well the design of their other elements towards clearly conveying the information to the end users.

Several methods of presenting classification data are detailed in the specialized literature: Natural Breaks, Nested Means, Mean and Standard Deviation, Equal Interval, Equal Frequency, Arithmetic and Geometric Interval and User Defined method (Dent et al., 2009). Many of these are implemented in cartographic software. In the present article, we analyzed those implemented in 
ArcGIS Pro, which was used for designing thematic maps.

\section{Materials and methods}

To provide examples for the above, several bivariate thematic maps were made, illustrating the relationship between the total number of calls to the unique emergency number 112 and the actual emergency calls (https://www.sts.ro/ ro/statistici-112) to the population of Romanian counties on $1^{\text {st }}$ July 2018 (http://statistici.insse. ro:8077/tempo-online/\#/pages/tables/inssetable). The first variable is represented by the ratio between the total number of 112 calls recorded in 2018 and the population of counties. The second chosen variable was the total number of emergency calls registered during the same interval of time.

As not all data on a map can be represented using a single symbol, this can lead to a complicated and unintelligible map and so the presented data must be classified. For this purpose, research data is classified using all of the methods available in ArcGIS Pro, which are briefly presented below.

\section{Natural breaks}

If the data is represented graphically, for example using a scatter plot, then it can be observed that all elements are grouped into a number of classes that are normally separated by empty spaces. The limits of these classes can be considered as the natural limits of those respective classes, thereby the resulting method appearing very intuitive. However, this solution is not as simple as it would seem. Obviously, the number of classes obtained via natural breaks might not coincide with the number of classes set by the cartographer. Therefore, the classes must be grouped so that the difference between the elements that make up a class will be minimal, while the difference between two adjacent classes needs to be significant. Another disadvantage of this method is that there may be classes that contain only one element. This usually happens when the data has not been uniformly distributed.

An iterative algorithm of establishing data belonging to the same class based on this particular method was proposed by Walter Fisher in 1958 and implemented by George Jenks in 1977 (Dent et al., 2009). The method analyses the sum of deviation for each class about its median and the smaller this value is, the more homogeneous the classes will be. This method can be implemented in ArcGIS as Natural Brakes (Jenks).

\section{Quantile}

In order to classify data via this method, all elements are ordered according to their rank, after which they are divided by the number of classes. Therefore, all classes have the same number of elements or equal frequency. If the total number of elements is not divisible to the number of classes, the remained will be distributed equally to the lower class ranges. Normally, this method divides elements into four or five classes, resulting in $20 \%-25 \%$ of values per each class, which would be easy to understand for most users. Another advantage is that there will be no resulting classes bereft of any element.

\section{Equal interval}

This is another method that is easy to both understand and calculate for most users because the amplitude of the data set is divided by the number of classes. The resulting classes will have the same width, but some of them may end up without any elements.

\section{Geometric interval}

This method of classification is applied in the case of value ranges which do not have a normal distribution and whose graphical representation is similar to that of a geometric progression, the class limits being established based on the data's rate of change. It is useful for continuous data featuring a wide range. This method is definitely not as easy to understand for those users who do not have specialized training.

\section{Standard deviation}

With this method, data can be classified if they have a normal distribution. The class breaks are established based on the mean and the standard deviation of the represented values. More precisely, a proportion of the standard deviation is added or subtracted from the mean value. Thus, an even number of equal interval classes will be obtained.

\section{Defined interval}

The end user can establish the interval size according to which the number of classes will be afterwards calculated.

\section{Manual interval (User defined)}

This method, as its name suggests, allows the mapmaker to set the class limits based on his/her individual knowledge and experience in order to enhance specific value ranges. 
In order to analyze the quality of classification, Slocum et al. (2010) propose to compare the value of the goodness of the absolute deviation fit to 1 according to the equation below, thus considering a value of at least 0.8 as indicative of a good classification. Dent et al. (2009), using the same procedure, accept a value of 0.7 towards the same conclusion.

$$
\mathrm{GADF}=1-\frac{\mathrm{ADCM}}{\mathrm{ADAM}}
$$

Where:

GADF - the value of goodness of absolute deviation fit;

ADCM - the sum of absolute deviation of values from one class from the class median;

ADAM - the sum of absolute deviations of the values

from the entire data set from its median.

\section{Results and discussion}

For each of the seven methods that can be used in ArcGIS Pro for data classification, the GADF was calculated both for the emergency calls (Tab. 1) and the ratio between the total calls and the county populations (Tab. 2). Accepting the default number of classes, namely five, the greatest value obtained for GADF for emergency calls classification was 0.82 via the Natural breaks method, followed by 0.76 for the Geometric interval method, 0.66 for the Manual interval, 0.55 in case of Manual interval, 0.51 for Standard deviation, 0.50 for Equal interval and 0.49 for Quantile. Therefore, the Natural breaks emerged as the best option from this point of view, being greater than the value indicated by Slocum et al. (2010). Instead, if we considered the lower limit suggested by Dent et al. (2009), the Geometric interval method of classification could be applied just as well.

Performing the same analysis in case of the ratio between the total calls and county population classification, none of the methods met the condition set by Slocum et al. (2010), while five of them fulfilled the condition of Dent et al. (2009): Natural breaks -0.78, Equal interval -0.77 , Geometric interval and Standard deviation -0.73 , and Quantile -0.70. In this case, the Defined interval method divided values into just three classes and thus could not be used towards the comparison made above.

In order to analyse the data represented on thematic maps, it is sometimes useful to compare maps of the same data created using different methods, or maps of correlated data designed using the same method. Slocum et al. (2010) stated that the Quantile method is useful when data sets of different distributions are to be compared, due to its property of dividing data in classes featuring the same number of elements. The Standard deviation method is also useful because it groups the elements symmetrically to the data set median based on the standard deviation, being thus suitable for data series with a uniform distribution. As opposed to these methods, the Natural breaks method classifies values according to their distribution on the number axis and thus loses the connection between the analysed elements.

In light of the above, comparing the choropleth map of standardised total number of 112 calls and the proportional symbol map of the raw number of emergency calls created the Quantile method (Fig. 3 ), it can be seen that the counties with the greatest problems are Bucharest-Ilfov, Cluj and Iasi. There one can find not only the greatest number of real emergencies, but also the greatest number of 112
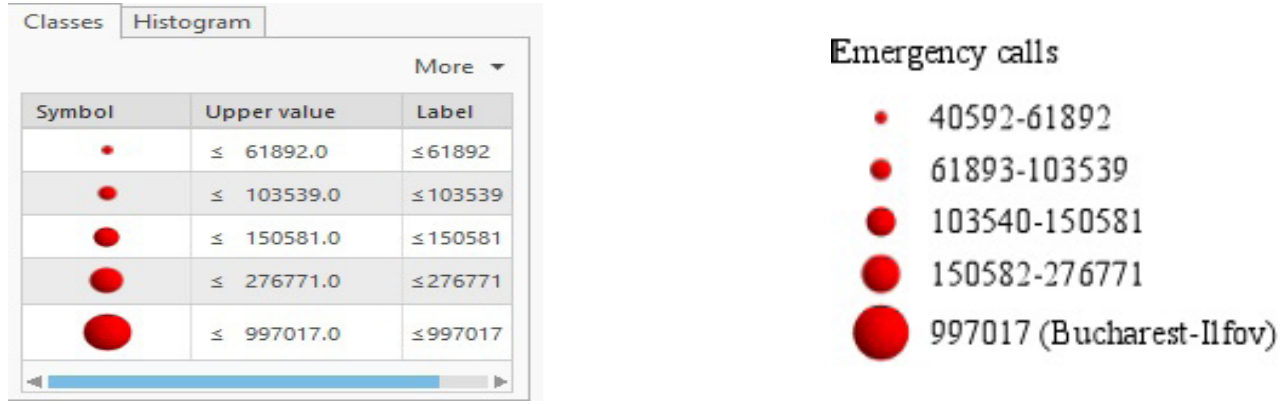

Figure 1. Legend of the thematic map in default (left) and explicit version (right) 
Table 1. Comparison of the GADF calculated using various methods of emergency calls classification (Data set median $=103539$ and ADAM $=2425928$ )

\begin{tabular}{|c|c|c|c|c|c|c|}
\hline Method & $\begin{array}{c}\text { Class } \\
\text { number }\end{array}$ & Class limits & $\begin{array}{l}\text { Number of } \\
\text { elements }\end{array}$ & $\begin{array}{c}\text { Class } \\
\text { median }\end{array}$ & ADCM & GADF \\
\hline \multirow{5}{*}{$\begin{array}{l}\text { Natural breaks } \\
\quad \text { (Jenks) }\end{array}$} & 1 & $40592-61892$ & 5 & 55477 & 28568 & \multirow{5}{*}{0.82} \\
\hline & 2 & 61893-103539 & 16 & 90682 & 120030 & \\
\hline & 3 & $103540-150581$ & 13 & 132423 & 123729 & \\
\hline & 4 & $150582-276771$ & 6 & 208287 & 169469 & \\
\hline & 5 & $276772-997017$ & 1 & 997017 & 0 & \\
\hline \multirow{5}{*}{ Quantile } & 1 & $40592-84621$ & 9 & 61892 & 84483 & \multirow{5}{*}{0.49} \\
\hline & 2 & $84622-97672$ & 8 & 90682 & 32822 & \\
\hline & 3 & $97673-117406$ & 8 & 109011 & 65263 & \\
\hline & 4 & $117407-147303$ & 8 & 133358 & 40024 & \\
\hline & 5 & 147304-997017 & 8 & 208287 & 1015905 & \\
\hline \multirow{5}{*}{ Equal interval } & 1 & $40592-231877$ & 38 & 99333 & 1196903 & \multirow{5}{*}{0.50} \\
\hline & 2 & $231878-423162$ & 2 & 268052.5 & 17437 & \\
\hline & 3 & $423163-614447$ & 0 & 0 & 0 & \\
\hline & 4 & 614448-805732 & 0 & 0 & 0 & \\
\hline & 5 & $805733-997017$ & 1 & 997017 & 0 & \\
\hline \multirow{5}{*}{$\begin{array}{l}\text { Geometric } \\
\text { interval }\end{array}$} & 1 & $40592-86204$ & 11 & 73990 & 134743 & \multirow{5}{*}{0.76} \\
\hline & 2 & $86205-98038$ & 8 & 95346.5 & 24684 & \\
\hline & 3 & $98039-143650$ & 13 & 128375 & 143007 & \\
\hline & 4 & 143651-319449 & 8 & 198384 & 272389 & \\
\hline & 5 & $319450-997017$ & 1 & 997017 & 0 & \\
\hline \multirow{5}{*}{$\begin{array}{l}\text { Standard } \\
\text { deviation }\end{array}$} & 1 & $40592-67677$ & 5 & 55477 & 273471 & \multirow{5}{*}{0.51} \\
\hline & 2 & $67678-212751$ & 32 & 109011 & 846566 & \\
\hline & 3 & $212752-357825$ & 3 & 259334 & 60599 & \\
\hline & 4 & 357826-502899 & 0 & 0 & 0 & \\
\hline & 5 & $502900-997017$ & 1 & 997017 & 0 & \\
\hline \multirow{5}{*}{ Defined interval } & 1 & $40592-200000$ & 36 & 98060 & 977103 & \multirow{5}{*}{0.55} \\
\hline & 2 & 200001-400000 & 4 & 237753 & 119531 & \\
\hline & 3 & 400001-600000 & 0 & 0 & 0 & \\
\hline & 4 & 600001-800000 & 0 & 0 & 0 & \\
\hline & 5 & 800001-997017 & 1 & 997017 & 0 & \\
\hline \multirow{5}{*}{ Manual interval } & 1 & $40592-140214$ & 31 & 95403 & 640191 & \multirow{5}{*}{0.66} \\
\hline & 2 & $140215-231941$ & 7 & 186040 & 172221 & \\
\hline & 3 & $231942-323712$ & 2 & 268052.5 & 17437 & \\
\hline & 4 & $323713-997016$ & 0 & 0 & 0 & \\
\hline & 5 & 997017 & 1 & 997017 & 0 & \\
\hline
\end{tabular}


Table 2. Comparison of the GADF calculated with various methods of the ratio between total emergency calls and population classification (Data set median $=0.81$ and $\mathrm{ADAM}=4.84$ )

\begin{tabular}{|c|c|c|c|c|c|c|}
\hline Method & $\begin{array}{c}\text { Class } \\
\text { number }\end{array}$ & Class limits & $\begin{array}{l}\text { Number of } \\
\text { elements }\end{array}$ & $\begin{array}{c}\text { Class } \\
\text { median }\end{array}$ & ADCM & GADF \\
\hline \multirow{5}{*}{$\begin{array}{l}\text { Natural breaks } \\
\text { (Jenks) }\end{array}$} & 1 & $0.57-0.70$ & 7 & 0.664706 & 0.23738 & \multirow{5}{*}{0.78} \\
\hline & 2 & $0.71-0.81$ & 14 & 0.770847 & 0.327371 & \\
\hline & 3 & $0.82-0.90$ & 9 & 0.866836 & 0.213219 & \\
\hline & 4 & 0.91-1.06 & 7 & 0.987159 & 0.180971 & \\
\hline & 5 & $1.07-1.19$ & 4 & 1.15365 & 0.088289 & \\
\hline \multirow{5}{*}{ Quantile } & 1 & $0.57-0.73$ & 9 & 0.680506 & 0.342107 & \multirow{5}{*}{0.70} \\
\hline & 2 & $0.74-0.79$ & 8 & 0.761227 & 0.107661 & \\
\hline & 3 & 0.80-0.86 & 8 & 0.815493 & 0.156873 & \\
\hline & 4 & 0.87-0.99 & 8 & 0.897004 & 0.267102 & \\
\hline & 5 & $1.00-1.19$ & 8 & 1.091932 & 0.560924 & \\
\hline \multirow{5}{*}{ Equal interval } & 1 & 0.57-0.69 & 6 & 0.653121 & 0.198637 & \multirow{5}{*}{0.77} \\
\hline & 2 & $0.70-0.82$ & 17 & 0.780246 & 0.491714 & \\
\hline & 3 & $0.83-0.94$ & 8 & 0.884314 & 0.175891 & \\
\hline & 4 & $0.95-1.07$ & 6 & 0.990582 & 0.135366 & \\
\hline & 5 & $1.08-1.19$ & 4 & 1.15365 & 0.088289 & \\
\hline \multirow{5}{*}{$\begin{array}{l}\text { Geometric } \\
\text { interval }\end{array}$} & 1 & $0.57-0.68$ & 5 & 0.641536 & 0.148754 & \multirow{5}{*}{0.73} \\
\hline & 2 & $0.69-0.77$ & 9 & 0.74906 & 0.179064 & \\
\hline & 3 & $0.78-0.88$ & 13 & 0.810081 & 0.356136 & \\
\hline & 4 & $0.89-1.02$ & 8 & 0.957115 & 0.316821 & \\
\hline & 5 & $1.03-1.19$ & 6 & 1.13553 & 0.284546 & \\
\hline \multirow{5}{*}{$\begin{array}{l}\text { Standard } \\
\text { deviation }\end{array}$} & 1 & $0.57-0.62$ & 2 & 0.598229 & 0.059804 & \multirow{5}{*}{0.73} \\
\hline & 2 & $0.63-0.77$ & 12 & 0.724969 & 0.393534 & \\
\hline & 3 & $0.78-0.92$ & 16 & 0.82402 & 0.58684 & \\
\hline & 4 & $0.93-1.07$ & 7 & 0.987159 & 0.180971 & \\
\hline & 5 & $1.08-1.19$ & 4 & 1.15365 & 0.088289 & \\
\hline \multirow{5}{*}{ Defined interval } & 1 & $0.57-0.72$ & 8 & 0.672606 & 0.296534 & \multirow{5}{*}{0.57} \\
\hline & 2 & 0.73-0.96 & 23 & 0.797882 & 1.089235 & \\
\hline & 3 & 0.97-1.19 & 10 & 1.044161 & 0.711304 & \\
\hline & 4 & - & - & - & - & \\
\hline & 5 & - & - & - & - & \\
\hline \multirow{5}{*}{ Manual interval } & 1 & $0.57-0.63$ & 2 & 0.598229 & 0.059804 & \multirow{5}{*}{0.69} \\
\hline & 2 & $0.64-0.70$ & 5 & 0.680506 & 0.088626 & \\
\hline & 3 & $0.71-0.88$ & 20 & 0.790271 & 0.708271 & \\
\hline & 4 & $0.89-1.13$ & 11 & 0.987128 & 0.601435 & \\
\hline & 5 & $1.14-1.19$ & 3 & 1.16501 & 0.052051 & \\
\hline
\end{tabular}



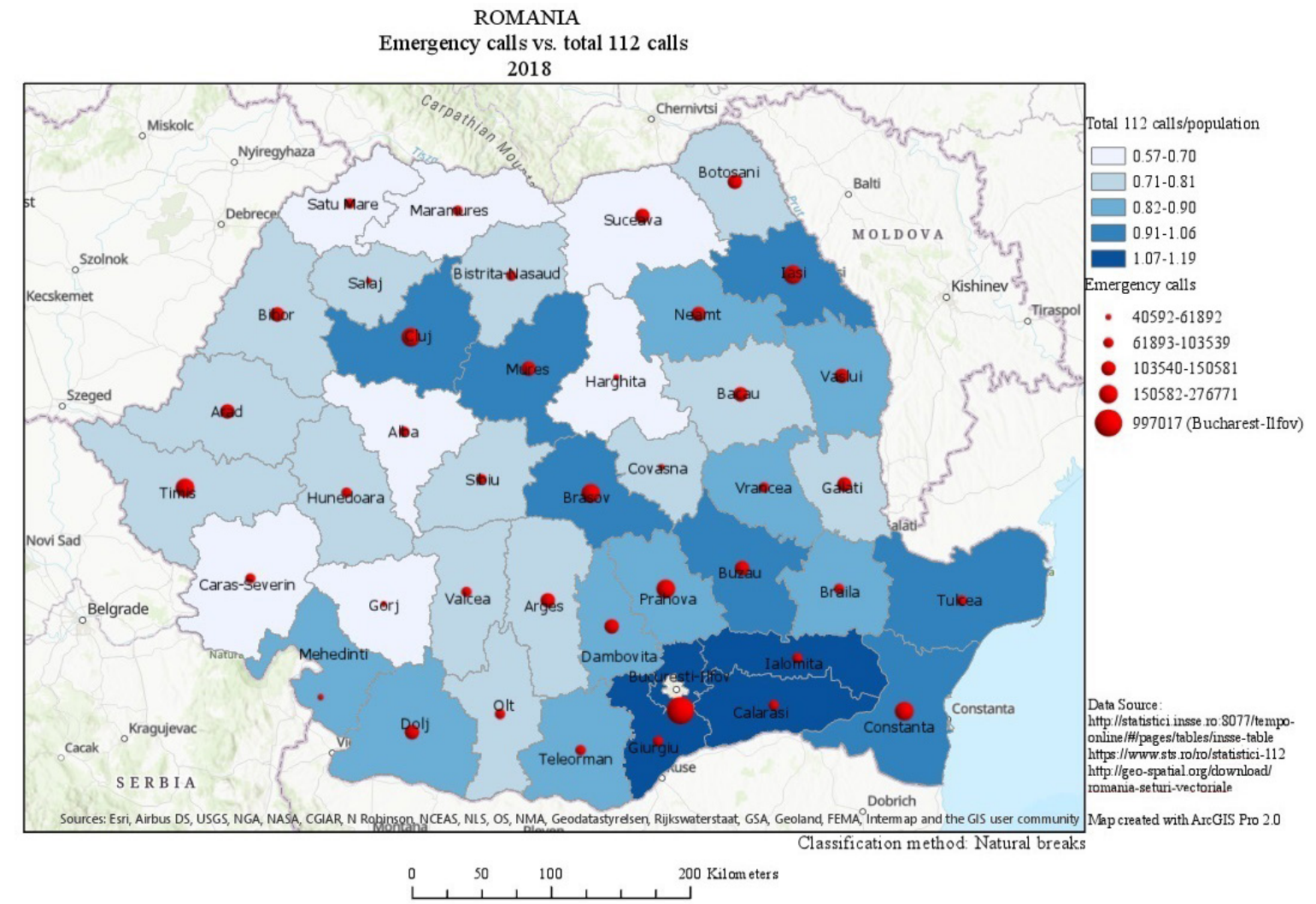

Figure 2. Thematic map created using the Natural breaks method of classification

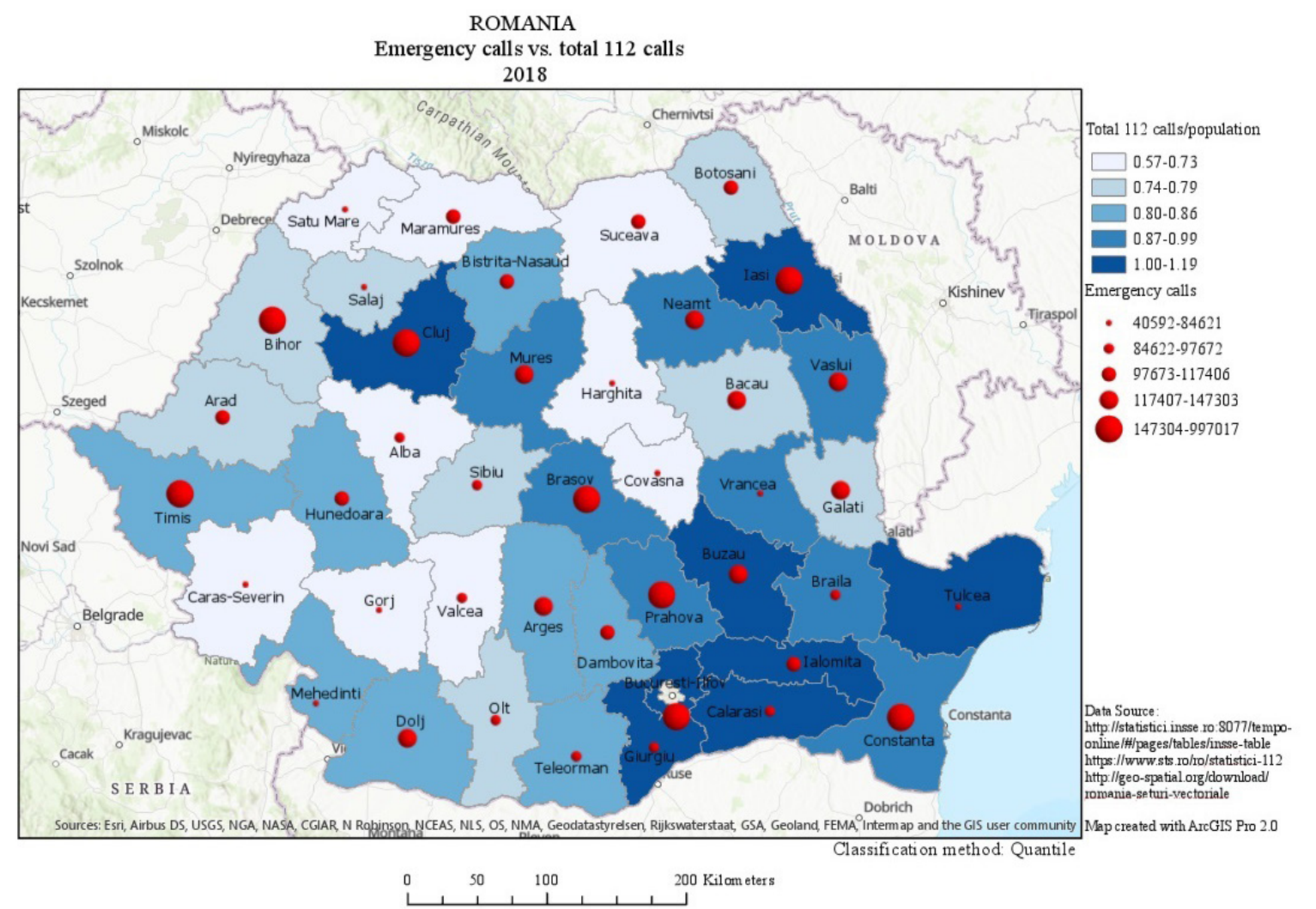

Figure 3. Thematic map created using the Quantile method of classification 


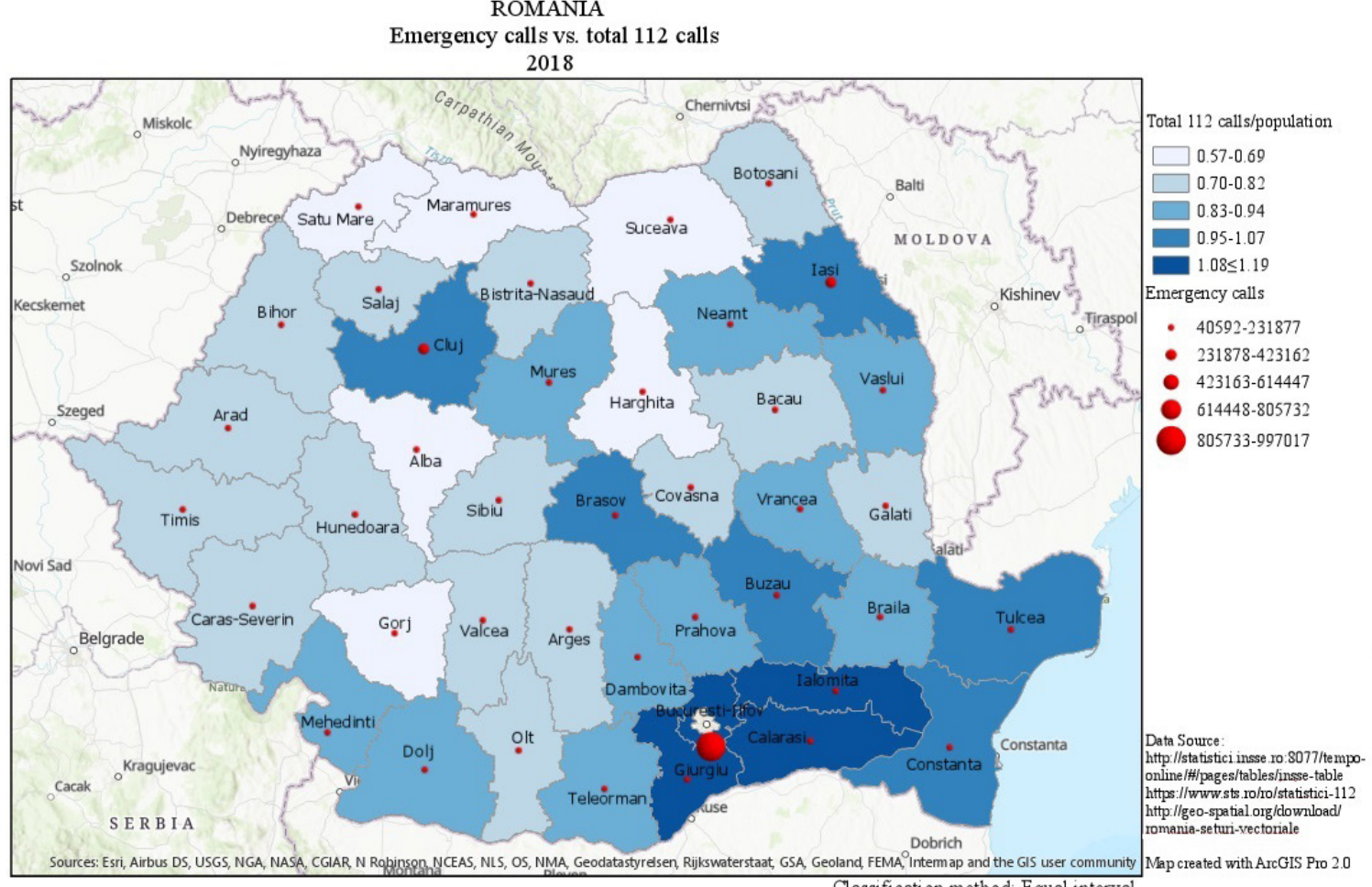

Classification method Equa

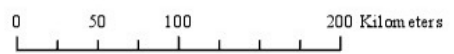

Figure 4. Thematic map created using the Equal interval method of classification
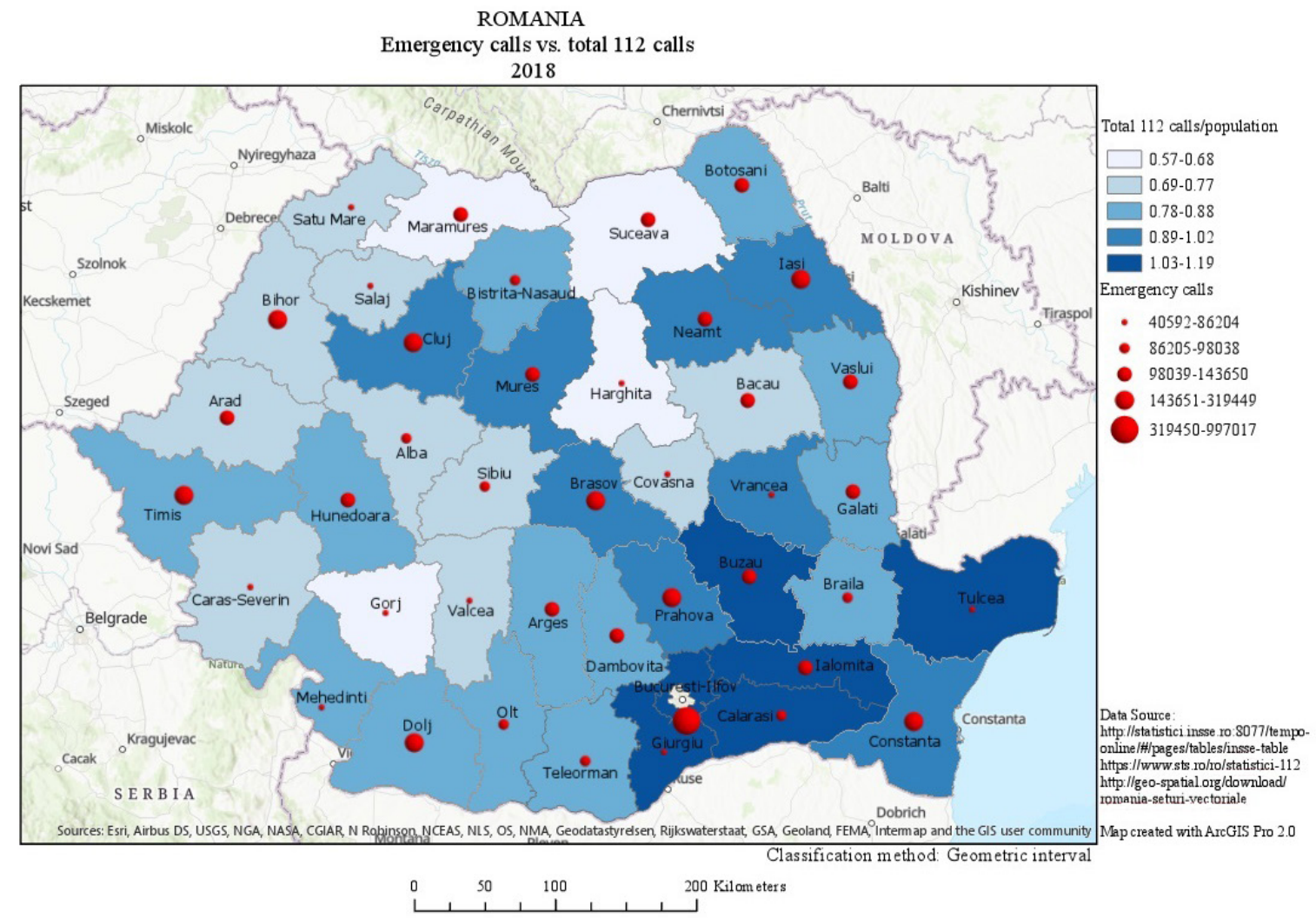

Figure 5. Thematic map created using the Geometric interval method of classification 


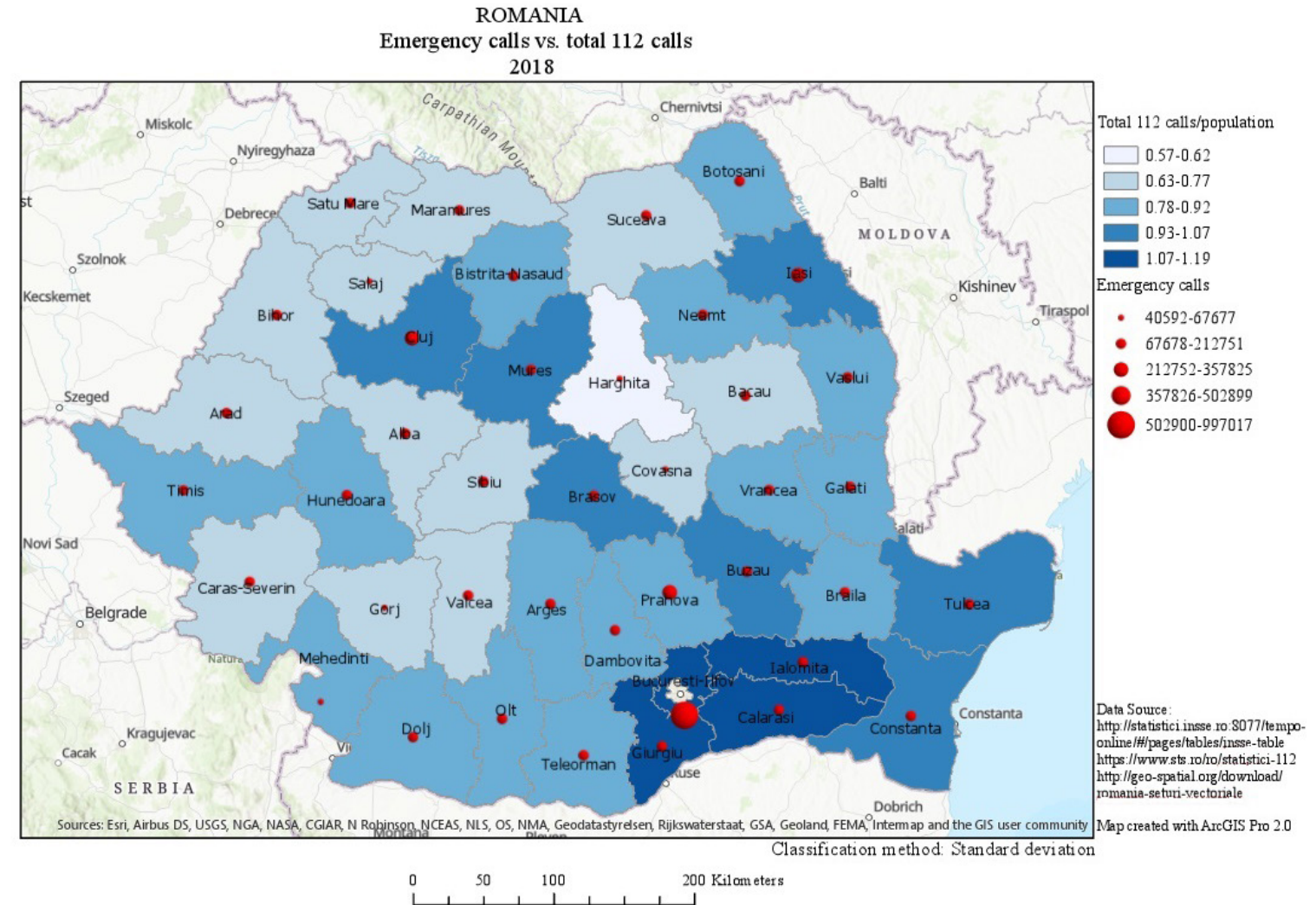

Figure 6. Thematic map created using the Standard deviation method of classification

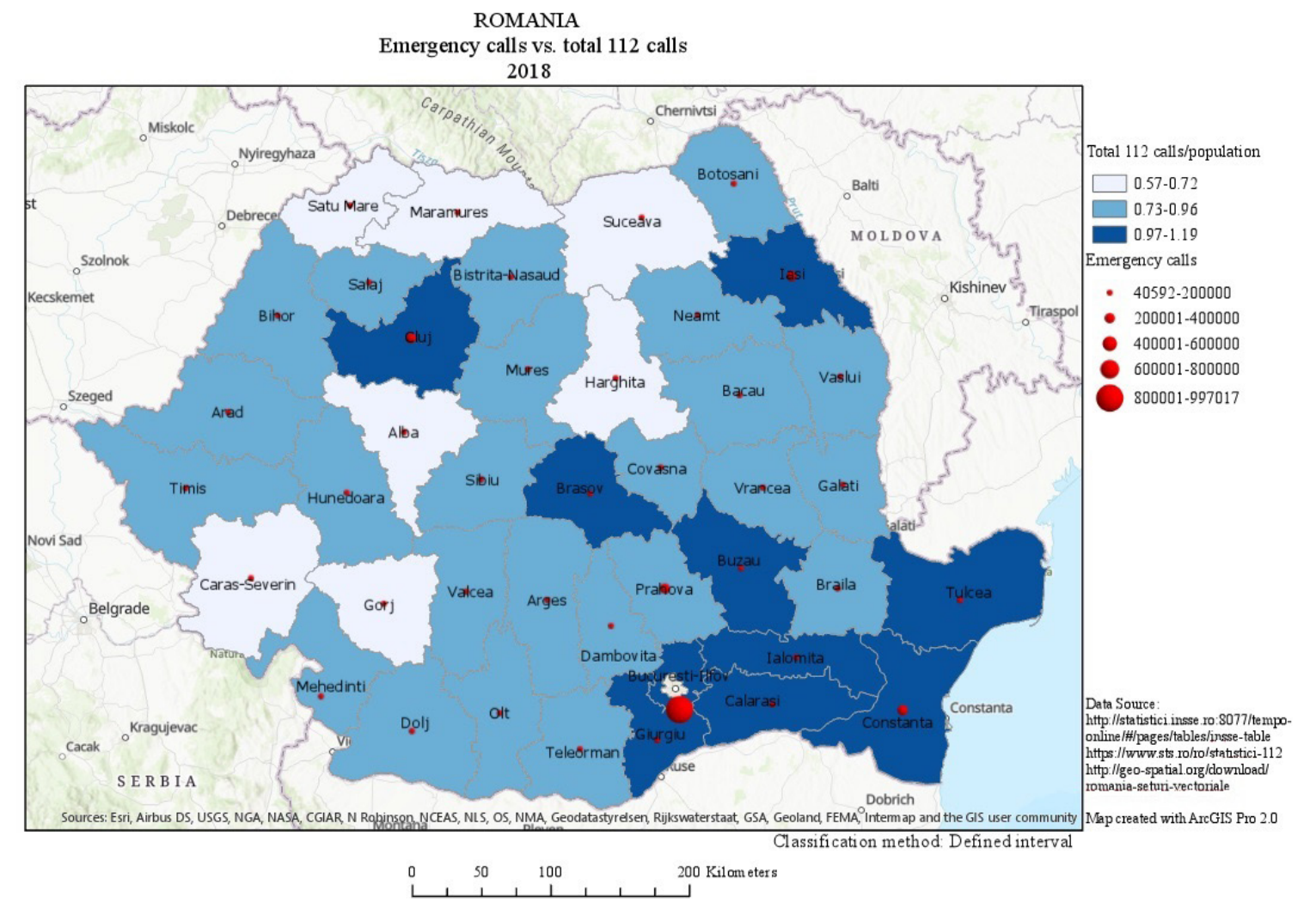

Figure 7. Thematic map created using the Defined interval method of classification 


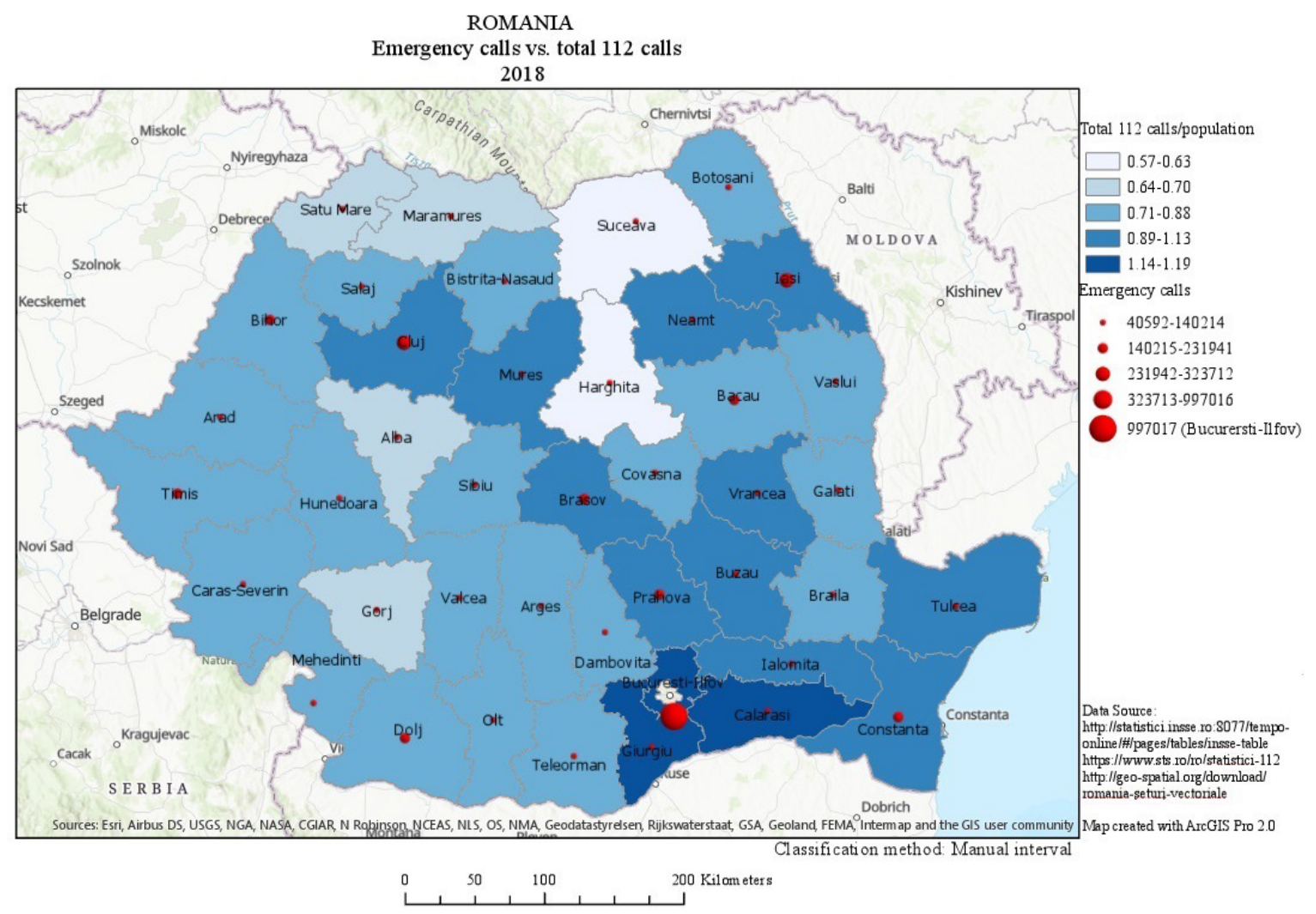

Figure 8. Thematic map created using the Manual interval method of classification

calls per capita, which could reasonably lead to overload of the intervention teams. These counties are immediately followed by Constanta, Prahova and Brasov, suggesting that similar problems must be solved there too.

Regarding the clarity of the information transmitted by a thematic map, it is not just the map itself that is important, but also its other elements, such as its title, legend, scale and source of data. The title of the map should reflect the subject being represented. The legend should be clear and easy to understand. This can be achieved by explicitly writing the boundaries of each class and not accepting the default versions, which give only the upper limit of each class (Fig. 1). Furthermore, the title of the legend should be clear and consistent with the title of the overall map. Regarding the scale, if the map is printed in various publications across different formats, it would be useful to be presented as a scale bar, in which case the mapmaker must be careful to only use multiples of map units, i.e. 100 kilometres on the maps presented below (Fig. 2-8). The data sources are important too, since they denote the degree of confidence in the represented data.
The limits of counties represented on these maps were imported from http://geo-spatial.org/ download/romania-seturi-vectoriale.

\section{Conclusion}

The different methods of data classification produce different thematic maps, each with their own advantages and disadvantages. In this article, we analyzed the methods that are available via ArcGIS Pro from the perspective of the value of goodness of absolute deviation fit (GADF), which was defined according to the deviations from the values to the median of the class to which they belonged and to the median of the entire data set. The highest value for GADF was obtained using the method of Natural Breaks (Jenks) for both data sets: 0.82 for emergency calls and 0.78 for the ratio between the total number of calls and the county populations.

The seven different thematic maps presenting the data sets mentioned above were created using these methods of classification in order to highlight that choosing the appropriate method is a decisive factor towards the aspect and suggestiveness of the resulting map. There are situations in which 
it is important to analyze the maps created via different methods so as to highlight those areas with the biggest problems. Thus, for the data series considered in this study, we have emphasized the counties with the greatest number of 112 calls per capita and the greatest number of emergencies calls overall, thus offering decision makers an instrument for properly sizing and relocating the intervention forces.

For achieving a better conveyance of information to the end users, special attention must be paid to the other elements of the thematic map and first of all to the map's legend.

The information presented in this article could be useful to those non-specialist mapmakers that want to represent and analyze their own data sets and thereby take the best decisions in their field of activity.

\section{References}

1. Dent B, Torguson J, Hodler T (2009). Cartography: Thematic Map Design, Sixth Edition. McGraw Hill Higher Education, New York: 85-99.

2. Slocum T, McMaster R, Kessler F, Howard H, (2010), Thematic Cartography and Geovizualization, Third Edition, Pearson Prentice Hall, Pearson Education, New Jersey: 57-75, 328-335.

3. http://statistici.insse.ro:8077/tempo-online/\#/pages/ tables/insse-table

4. https://www.sts.ro/ro/statistici-112

5. http://geo-spatial.org/download/romania-seturivectoriale 